\title{
Improving Phonological Awareness in Parents of Children at Risk of Literacy Difficulties: A Preliminary Evaluation of the Boost Program
}

OPEN ACCESS

Edited by: Nicola Pitchford,

University of Nottingham, United Kingdom

Reviewed by: Alison W. Arrow,

Massey University, New Zealand Jaclyn M. Dynia,

The Ohio State University Columbus, United States

*Correspondence: Mark E. Boyes

mark.boyes@curtin.edu.au

Specialty section:

This article was submitted to

Educational Psychology,

a section of the journal

Frontiers in Education

Received: 08 June 2017 Accepted: 23 August 2017 Published: 06 September 2017

Citation:

Boyes ME, Leitão S, Claessen M

Dzidic P, Boyle G, Perry A and

Nayton M (2017) Improving Phonological Awareness in Parents

of Children at Risk of Literacy Difficulties: A Preliminary Evaluation of the Boost Program.

Front. Educ. 2:47.

doi: 10.3389/feduc.2017.00047

\section{Mark E. Boyes ${ }^{1 *}$, Suze Leitão ${ }^{1}$, Mary Claessen ${ }^{1}$, Peta Dzidic $^{1}$, Gemma Boyle ${ }^{2}$, Alison Perry ${ }^{2}$ and Mandy Nayton ${ }^{2}$}

${ }^{1}$ Faculty of Health Sciences, School of Psychology and Speech Pathology, Curtin University, Perth, WA, Australia,

${ }^{2}$ The Dyslexia-SPELD Foundation, Perth, WA, Australia

Background: Phonological awareness is an important skill underpinning the development of early literacy. Given the central role of parents in supporting the development of children's early literacy skills, and that poor parental phonological awareness is associated with poorer child literacy outcomes, it is possible that improving parent phonological awareness may aid literacy development for at-risk children. This study is a preliminary evaluation of a program aiming to improve phonological awareness skills of parents in low socioeconomic status communities, and also provide these parents with strategies to support their child's literacy development.

Methods: After completing the program, participants were asked if it had helped them learn about how to assist their child's reading and spelling, whether they planned on using the resources provided, and if they would be likely to attend a future workshop building on the Boost program. Phonological awareness measures (rhyme, syllable, and phoneme level), and measures of overall confidence in performance on the phonological awareness tasks, were administered both before and after attending the program.

Results: Almost all parents indicated that the program helped with learning how to assist their child's reading and spelling, that they would use the resources provided, and would likely attend a future workshop. Significant increases in pre- to post-program phonological awareness scores were obtained at the rhyme and phoneme level.

Conclusion: The program and associated resources appear acceptable to parents in communities with high rates of literacy problems and improved parents' phonological awareness skills. However, findings are preliminary and further evaluation using more rigorous methodologies and testing whether improvements in parents' phonological awareness translate into better literacy outcomes for children is needed.

Keywords: phonological awareness, literacy, reading, parent, child, intervention

\section{INTRODUCTION}

Approximately 25\% of students in Australia achieve literacy levels at or below minimum standards (Australian Curriculum Assessment and Reporting Authority, 2012; Hempenstall, 2016). Reading development, in particular in the early years of schooling, is a strong predictor of later academic success, as well as psychosocial wellbeing (Boyes et al., 2016; Snow, 2016). The findings 
of three major inquiries into the teaching of reading (National Institute of Child Health and Human Development, 2000; Rowe and National Inquiry into the Teaching of Reading, 2005; Rose, 2009) have provided strong evidence for the important role played by phonological awareness in the development of foundational reading skills (Hempenstall, 2016; Snow, 2016). Given the central role of parents in supporting the development of children's early literacy skills (i.e., reading and spelling) and that poor parental phonological awareness is associated with poorer child literacy outcomes (Heath et al., 2014), it is plausible that improving parent phonological awareness may aid literacy development for at-risk children. The current study provides a preliminary evaluation of a program aiming to improve phonological awareness skills of parents in low socioeconomic status communities with high rates of poor literacy.

Phonological awareness is the explicit knowledge of, and the ability to attend to and make judgments about, the sound structure of lexical items or words (Gillon, 2007; Schuele and Boudreau, 2008). The development of phonological awareness occurs along a continuum rather than in discrete stages, with development of linguistic (word, syllable, onset-rime, phoneme) and task (e.g., blending, deletion) complexity occurring concurrently (Anthony et al., 2003). The relationship between phonological awareness, in particular phonemic awareness, and early reading and spelling acquisition is now well documented (Ehri et al., 2001; Gillon, 2007). Specifically, understanding the phonemic structure of words is of key importance in supporting "cracking" the alphabetic code, and hence the transition to reading and writing in young children (Schuele and Boudreau, 2008). Consistent with this, a large proportion of children with reading difficulties present with underlying deficits in phonological awareness skills (Share and Stanovich, 1995). Furthermore, children who experience phonological awareness difficulties in their early years often continue to fall behind their peers (Moore et al., 2005), with the effects of early reading difficulties being long lasting (Juel, 1988).

Importantly, parents play a crucial role in developing children's early literacy skills (Snow et al., 1998). Additionally, there is a substantial evidence for the aggregation of reading and literacy difficulties in families, reflecting both genetic and environmental factors (Byrne et al., 2009). Recent Australian research reports that children with three or more family risk factors (including low socioeconomic status, family history of literacy problems, and poor parent phonological awareness) were found to have poorer pre-literacy skills, as well as poorer later literacy outcomes than children with fewer family risk factors (Heath et al., 2014). However, almost no research has specifically examined the effect of parent teaching, or scaffolding, of young children's phonological awareness skills on child literacy outcomes (Skibbe et al., 2004). A study by Skibbe et al. (2011) demonstrated a small but significant increase in child phonological awareness scores in the context of a book-sharing program, in which parents read books with their children using scripted comments/questions designed to focus attention on phonological awareness. Similarly, a recent book-sharing study demonstrated improvements in expressive vocabulary and concepts about print and rhyme, although no improvements in child phonemic awareness or receptive vocabulary were observed (Sim et al., 2014).

One key aspect of family background yet to be explored in detail, and which was not measured in the Skibbe et al. (2011) and Sim et al. (2014) studies, is parental phonological awareness skills. To date, there has been no research testing whether improving parent phonological awareness is associated with improvements in child literacy. However, given (i) the aggregation of literacy difficulties in families (Byrne et al., 2009), (ii) that adults with reading difficulties often exhibit poor phonological awareness (Bruck, 1993; Gillon, 2007), and (iii) poor parental phonological awareness is associated with poorer child literacy outcomes (Heath et al., 2014), it is at least plausible that improving parents' phonological awareness skills may help support children's emerging literacy skills, specifically phonological awareness (Heath et al., 2014), and particularly when complemented with concrete strategies for developing children's early literacy skills.

The Boost program was developed in 2010 by the DyslexiaSPELD Foundation (Perth, WA, Australia) and aims to provide parents of children aged 4-7 years living in high-risk (low socioeconomic) communities with the knowledge to support their child's literacy development (DSF Literacy and Clinical Services, 2013). The program has particular focus on the development of phonological awareness, linked to learning about the alphabet and early phoneme-grapheme mapping. This is complemented by discussion and modeling of the use of dialogic reading strategies to develop vocabulary and comprehension, and a focus on print referencing techniques to support early alphabet knowledge and phonics. The use of the phonemic awareness skills of blending and segmenting when reading and spelling is highlighted in the sessions. Boost aims to empower parents to support their children's literacy development when they are just beginning school, thereby aiming to reduce academic difficulties throughout their schooling and beyond. Boost provides parents with user-friendly information and low-cost, practical strategies, activities, and materials to build their literacy skills and prevent literacy failure.

Parents attend two half-day practical workshops in which they learn about the research and evidence underlying literacy development in the early years and are provided with the opportunity to practice games and strategies to scaffold literacy development. Following discussions, parents carry out phonological awareness activities and practice early phonemegrapheme mapping. Parents are also provided (at no cost) with a comprehensive take-home kit containing reading materials, language and rhyming cards, phonics resources, a booklet containing additional information and low-cost activity ideas, and an instructional DVD. These kits encourage parents to actively implement their learning at home. Overall, Boost targets the following factors highlighted as critically important in the effective teaching of reading (Hempenstall, 2016): explicit and systematic phonemic awareness instruction (Schuele and Boudreau, 2008), systematically sequenced phonics instruction (Foorman et al., 1997), guided and repeated oral reading with appropriate error correction and feedback to improve reading fluency (Begeny et al., 2010), and direct instruction in 
vocabulary and reading comprehension strategies (Clarke et al., 2010; Sinatra et al., 2011).

The aim of the current study was to conduct a preliminary evaluation of the Boost program. Program acceptability was assessed by examining dropout rates, characteristics of parents who did and did not complete the program, whether parents planned on using the resources provided, and the likelihood of parents attending any future workshop building on the program. The effectiveness of the program was assessed by evaluating whether the program helped parents learn how to assist their child's reading and spelling and testing whether program attendance resulted in improvements in parent phonological awareness skills. It was hypothesized that after attending the Boost program parents would obtain higher scores on objective tests of phonological awareness than they did prior to attending the program.

\section{MATERIALS AND METHODS}

\section{Participants}

This study is a secondary analysis of data collected in 2016 by the Dyslexia-SPELD foundation for their own evaluation purposes. Data were available from six Boost program implementations conducted at six primary schools in disadvantaged areas of Western Australia (98 individual participants). Of the 98 participants, $86(88 \%)$ completed the two part program and provided data at both pre- and post-program assessments. Data were completely anonymous, so no demographic information about the sample is available; however, all participants were parents of children aged between 4 and 7 years attending schools in low socioeconomic communities with high rates of literacy problems.

\section{Measures}

Measures of participants' phonological awareness (at the rhyme, syllable, and phoneme level) were administered before and after attending the Boost program. Participants also reported on their overall confidence in their responses to the rhyme, syllable, and phoneme assessments (1: not at all; 5: extremely) before and after completing the program.

\section{Rhyme}

Rhyming words share the same ending or "rime" (for example "an" is the rhyming part of tan, man and clan; e.g., Gillon, 2007). Participants were asked to generate a list of three words that rhymed with three base words (pre: lap, skin, wall; post: bat, stop, hill). Responses for each base word were scored as incorrect (0) or correct (1), and were only scored as correct if three appropriate rhyming words were generated. This provided a total rhyme score that could range between 0 and 3 at each assessment.

\section{Syllable}

A syllable is an uninterrupted unit of speech (or text) that has one vowel sound, with or without surrounding consonants, forming the whole or a part of a word (Gillon, 2007); for example the word "water" (wa/ter) has two syllables and "volcano" (vol/ca/no) has three syllables. Participants were asked to identify the number of syllables in four words (pre: caterpillar, attached, spring, butterfly; post: unicorn, believed, incredible, strong). These were scored as incorrect (0) or correct (1), providing a total syllable score that could range between 0 and 4 at each assessment.

\section{Phoneme}

Phonemes are the smallest units of speech which change meaning in a language. For example, the difference between hit/sit, hit/hot or hit/hid is a difference of only one phoneme (a single sound) in each case (e.g., Gillon, 2007). Participants were asked to identify the number of phonemes in four words (pre: ape, scratch, stung, meat; post: ice, stretch, swing, boat). These were scored as incorrect (0) or correct (1), providing a total phoneme score that could range between 0 and 4 at each assessment.

\section{Learning, Resource Use, and Future Program Attendance}

Finally, after completing the program, participants were asked if it had helped them learn about how to assist their child's reading and spelling (1: not much; 5: a lot), whether they planned on using the resources provided (1: not much; 5: a lot), and if they would attend another workshop building on the Boost program (0: no; 1: yes; 2: unsure).

\section{Procedure}

Parents attended two half-day workshops. Pre-program assessments were conducted at the beginning of the first workshop and post-program assessments were conducted at the end of the second workshop. All data were collected by the DyslexiaSPELD Foundation and an opt-out consent procedure was implemented; parents could indicate if they did not want their anonymous responses to be used for evaluation or research purposes. Data from participants who chose to opt-out was not provided to the researchers. Ethical approval for the secondary data analyses was obtained from the Curtin University Human Research Ethics Committee (HRE2017-0184). Given that (i) the data were completely anonymous (not even sociodemographic information such as age and gender was collected by the Dyslexia-SPELD Foundation) and (ii) participants had the option to indicate if they did not consent to their data being used for evaluation purposes, the Curtin University Human Research Ethics Committee deemed that a waiver of explicit consent was warranted.

\section{Analyses}

Analyses were conducted in three stages. First, we compared parents who did and did not complete the Boost program on pre-program phonological awareness scores. Second, the proportion of parents indicating that (i) the program helped them learn how to assist their child's reading and spelling, (ii) they intended to use the resources provided, and (iii) they would attend a future workshop was estimated. Finally, descriptive statistics for the phonological awareness skills (rhyme, syllable, and phoneme) and confidence scores were calculated for both 
pre- and post-program assessments. A series of repeatedmeasures ANOVAs were conducted to test whether phonological awareness and confidence improved after attending the program. Given that multiple repeated-measures analyses were conducted an alpha correction was applied $(\alpha=0.013)$.

\section{RESULTS}

\section{Phonological Awareness of Parents Who Did and Did Not Complete the Boost Program}

Baseline phonological awareness scores of parents who did and did not complete the Boost program are summarized in Table 1. In comparison with parents who did complete the program, parents who did not complete the program had significantly higher phoneme-level scores at baseline assessment and also reported significantly more confidence in their responses to the phonological awareness assessments.

\section{Learning, Utility of the Resources Provided, and Likelihood of Future Program Attendance}

Overall, participants who completed the program indicated that the it helped them learn how to assist their child's reading and spelling, with $78 \%$ of attendees indicating that it helped "A lot" $(\mathrm{M}=4.83, \mathrm{SD}=0.38)$. The majority of participants indicated that they intended to use the resources provided, with $70 \%$ of attendees indicating they intended to use them "A lot" $(M=4.72$, SD $=0.51)$. Similarly, almost all participants $(90 \%)$ who completed the program indicated that they would attend a future workshop building on the Boost program.

\section{Changes in Phonological Awareness and Confidence after Completing the Boost Program}

Mean rhyme, syllable, and phoneme scores before and after completing Boost program are summarized in Table 2. There were significant improvements in rhyme $[F(1,84)=13.48, p<0.001]$ and phoneme $[F(1,84)=58.95, p<0.001]$ scores from pre- to post-program assessment, as well as a significant increase in

TABLE 1 | Baseline phonological awareness scores of parents who did and did not complete the program.

\begin{tabular}{lcccc}
\hline & $\begin{array}{c}\text { Completed } \\
(\boldsymbol{n}=\mathbf{8 6})\end{array}$ & $\begin{array}{c}\text { Did not complete } \\
(\boldsymbol{n}=\mathbf{1 2})\end{array}$ & $\boldsymbol{p}$-Value & Cohen's $\boldsymbol{D}$ \\
\cline { 2 - 3 } & $\mathbf{M}$ (SD) & $\mathbf{M}$ (SD) & & \\
\hline Rhyme score & $2.11(1.18)$ & $1.92(1.31)$ & 0.608 & 0.15 \\
Syllable score & $3.21(1.08)$ & $2.92(1.62)$ & 0.410 & 0.21 \\
Phoneme score & $1.44(0.99)$ & $2.50(1.24)$ & $\mathbf{0 . 0 0 3}$ & 1.02 \\
Confidence & $3.03(1.05)$ & $3.73(0.90)$ & $\mathbf{0 . 0 2 3}$ & 0.71 \\
\hline
\end{tabular}

Significant $p$-values are bolded. Given the unequal sample sizes, $p$-values are associated with non-parametric Mann-Whitney U-tests.
TABLE 2 | Phonological awareness and confidence scores at pre- and postprogram assessments.

\begin{tabular}{lccrc}
\hline & Pre-program & Post-program & \multirow{2}{*}{$\boldsymbol{p}$-Value } & Cohen's $\boldsymbol{D}$ \\
\cline { 2 - 3 } & M (SD) & M (SD) & & \\
\hline Rhyme score & $2.11(1.18)$ & $2.59(0.81)$ & $<\mathbf{0 . 0 0 1}$ & 0.47 \\
Syllable score & $3.21(1.08)$ & $3.05(1.13)$ & 0.171 & 0.14 \\
Phoneme score & $1.44(0.99)$ & $2.59(1.23)$ & $<\mathbf{0 . 0 0 1}$ & 1.03 \\
Confidence & $3.02(1.05)$ & $3.68(0.86)$ & $<\mathbf{0 . 0 0 1}$ & 0.69 \\
\hline
\end{tabular}

Significant $p$-values are bolded (using a corrected alpha of $p<0.013)$. $p$-Values associated with repeated-measures ANOVAs.

overall participant confidence regarding their responses to the phonological awareness tasks $[F(1,81)=29.87, p<0.001]$. Changes in syllable scores before and after completing the program were non-significant $[F(1,84)=1.91, p .171]$.

\section{DISCUSSION}

The aim of the current study was to conduct a preliminary evaluation of the acceptability of the Boost program, and to test whether or not it equipped parents to support their child's literacy development and resulted in improvements in parent's phonological awareness skills.

From a program acceptability perspective, dropout rates were relatively low and parents who dropped out of the program had better phonological skills and confidence in their phonological awareness skills at pre-program assessment. This potentially suggests that parents who dropped out of the program did so because they felt they already had the skills the program aimed to teach. This should be taken into account when considering recruitment strategies for future implementations of the program. Although reasons for dropout need to be tested explicitly in future research, it is promising that the parents who should theoretically obtain the most benefit from the program are least likely to drop out of the program. The fact that $70 \%$ of parents who completed the program indicated that they intended to make extensive use of the resources provided, and that parents overwhelmingly indicated that they would attend a future workshop building on the Boost program, is additional evidence for the acceptability of the program and the associated resources.

Results also clearly demonstrated the effectiveness of the Boost program, reflected in both objective measures of parents' phonological awareness as well as parents' reports of the extent to which it equipped them to assist their child's reading and spelling. After completing the program, parents demonstrated significant improvements in phonological awareness skills, as well as in their confidence regarding their performance on the phonological awareness tasks. Specifically, there were modest improvements on rhyme awareness and no change in syllable awareness. However, there was a large improvement in parents' phonemic awareness skills. This is an important finding, as it indicates that participants attending the Boost workshops had an increased understanding of how to work with the individual sounds within words and is also consistent with research demonstrating that 
phonemic awareness in teachers can be improved with explicit instruction (Nicholson, 2007).

While all three levels of phonological awareness are important for literacy development, rhyme and syllable awareness are more likely to develop spontaneously-in contrast, phonemic awareness is a skill which requires more explicit instruction (National Institute of Child Health and Human Development, 2000; Foy and Mann, 2003; Gillon, 2007). Understanding the phonemic structure of words is of key importance in supporting the transition to reading and writing in young children (Schuele and Boudreau, 2008). Good phonemic awareness helps beginning readers understand the alphabetic principle; that written words are composed of letters that correspond to phonemes (Hempenstall, 2016). The increased levels of phonemic awareness developed by the parents in the Boost program is potentially a skill that parents can draw on in their interactions with their children to support their literacy development. Additionally, almost all participants indicated that the program equipped them to support their child's literacy development and intended to use the resources provided, indicating that the skills developed through participation in the Boost program are likely to be implemented with their children.

Although these findings are promising, they need to be interpreted in light of some methodological limitations and, given the secondary nature of the analyses, constraints of the dataset. First, the lack of a comparison group who did not attend the program precludes any conclusion that the improvements observed in phonological awareness arose as a direct result of program attendance. Any future evaluations of the program should incorporate a control group, preferably with random allocation to the intervention and control conditions. Second, ceiling effects may have constrained variability in the data, particularly for the self-report program ratings, and future evaluations should use more sensitive measures. Third, no sociodemographic information about the participants was recorded. Given the links between socioeconomic status and poor literacy and evidence for family history of literacy problems and gender being associated with literacy difficulties (Heath et al., 2014; Quinn and Wagner, 2015), it will be important to capture this information in future evaluations of the program. Fourth, although phoneme awareness and segmentation skills are important foundation skills for literacy development (Dodd and Gillon, 2001; Gillon, 2007; Lonigan et al., 2009), and it might be assumed that parents with good phoneme awareness are better able to support the development of their children's phoneme awareness, no data on child phonological awareness or literacy outcomes was available. Given that one of Boost's primary aims is to empower parents to support their children's literacy development, it will be important to measure child outcomes in any future evaluations of the program if conclusions regarding the transfer of benefits to children are to be made. Future investigations should consider direct assessment of children's phonological awareness on a valid and reliable measure such as the Preschool and Primary Inventory of Phonological Awareness
(Dodd et al., 2000), and appropriate measures of early reading and spelling, for example subtests from the Woodcock Reading Mastery Tests (Woodcock, 2011).

Bearing these limitations in mind, the Boost program and its associated resources appear to be acceptable to parents in communities with high rates of literacy problems. The program also improved parent's phonological awareness skills as well as parents' perceptions of their ability to assist their child's literacy development. Although the results should be considered preliminary in nature, taken together these findings are promising and suggest more rigorous evaluation of the Boost program is warranted to inform educational and clinical practice. Specifically, further research incorporating a control group and investigating whether improving parents' phonological awareness translates into improved literacy outcomes for at-risk children is clearly needed.

\section{ETHICS STATEMENT}

All data were collected by the Dyslexia-SPELD Foundation and an opt-out consent procedure was implemented; parents could indicate if they did not want their anonymous responses to be used for evaluation or research purposes. Data from participants who chose to opt-out was not provided to the researchers. Ethical approval for the secondary data analyses was obtained from the Curtin University Human Research Ethics Committee (HRE2017-0184). Given that (i) the data were completely anonymous (not even sociodemographic information such as age and gender was collected by the DyslexiaSPELD Foundation) and (ii) participants had the option to indicate if they did not consent to their data being used for evaluation purposes, the Curtin University Human Research Ethics Committee deemed that a waiver of explicit consent was warranted.

\section{AUTHOR CONTRIBUTIONS}

MB, SL, MC, PD, GB, AP, and MN conceived and designed the research. $\mathrm{MB}$ analyzed the data. $\mathrm{MB}$ and $\mathrm{SL}$ wrote the first draft of the manuscript. MC, $\mathrm{PD}, \mathrm{GB}, \mathrm{AP}$, and $\mathrm{MN}$ reviewed drafts of the manuscript.

\section{ACKNOWLEDGMENTS}

We would like to thank Tim Claessen for his help in constructing the database and entering the data.

\section{FUNDING}

This evaluation was funded by a grant from United Way West Australia and Community Link and Network Midland (CLAN Midland). The development of the Boost program was supported with funding from United Way West Australia. The implementation of the six Boost programs evaluated in this study was funded by United Way West Australia. 


\section{REFERENCES}

Anthony, J. L., Lonigan, C. J., Driscoll, K., Phillips, B. M., and Burgess, S. R. (2003). Preschool phonological sensitivity: a quasi-parallel progression of word structure units and cognitive operations. Read. Res. Q. 38, 470-487. doi:10.1598/ RRQ.38.4.3

Australian Curriculum Assessment and Reporting Authority. (2012). NAPLAN Achievement in Reading, Writing, Language Conventions and Numeracy: National Report for 2012. Sydney: ACARA.

Begeny, J. C., Laugle, K. M., Krouse, H. E., Lynn, A. E., Tayrose, M. P., and Stage, S. A. (2010). A control-group comparison of two reading fluency programs: the Helping Early Literacy with Practice Strategies (HELPS) Program and the Great Leaps K-2 Reading Program. School Psych. Rev. 39, 137-155.

Boyes, M. E., Leitao, S., Claessen, M., Badcock, N. A., and Nayton, M. (2016). Why are reading difficulties associated with mental health problems? Dyslexia 22, 263-266. doi:10.1002/dys.1531

Bruck, M. (1993). Word recognition and component phonological processing skills of adults with childhood diagnosis of dyslexia. Dev. Rev. 13, 258-268. doi:10.1006/drev.1993.1012

Byrne, B., Coventry, W. L., Olson, R. K., Samuelsson, S., Corley, R., Willcutt, E. G., et al. (2009). Genetic and environmental influences on aspects of literacy and language in early childhood: continuity and change from preschool to Grade 2. J. Neurolinguistics 22, 219-236. doi:10.1016/j.jneuroling.2008.09.003

Clarke, P., Snowling, M. J., Truelove, E., and Hulme, C. (2010). Ameliorating children's reading comprehension difficulties: a randomised controlled trial. Psychol. Sci. 21, 1106-1116. doi:10.1177/0956797610375449

Dodd, B., Crosbie, S., Macintosh, B., Teitzel, B., and Ozanne, A. (2000). The Primary and Preschool Inventory of Phonological Awareness. London: Psychological Corporation.

Dodd, B., and Gillon, G. (2001). Exploring the relationship between phonological awareness, speech impairment, and literacy. Adv. Speech Lang. Pathol. 3 , 139-170. doi:10.3109/14417040109003720

DSF Literacy and Clinical Services. (2013). Boost: Help Your Child to Read and Spell Workshop Booklet. Perth: The Dyslexia-SPELD Foundation.

Ehri, L. C., Nunes, S. R., Willows, D. M., Schuster, B. V., Yaghoub-Zadeh, Z., and Shanahan, T. (2001). Phonemic awareness instruction helps children learn to read: evidence from the National Reading Panel's Meta-Analysis. Read. Res. Q. 36, 250-287. doi:10.1598/RRQ.36.3.2

Foorman, B., Francis, D., Beeler, T., Winikates, D., and Fletcher, J. (1997). Early interventions for children with reading problems: study designs and preliminary findings. Learn. Disabil. 8, 63-71.

Foy, J. G., and Mann, V. (2003). Home literacy environment and phonological awareness in preschool children: differential effects for rhyme and phoneme awareness. Appl. Psycholinguist. 24, 59-88. doi:10.1017/S0142716403000043

Gillon, G. (2007). Phonological Awareness: From Research to Practice. New York: Guilford Press.

Heath, S. M., Bishop, D. V. M., Bloor, K., Boyle, G., Fletcher, J., Hogben, J., et al. (2014). A spotlight on preschool: the influence of family factors on children's early literacy skills. PLoS ONE 9:e95255. doi:10.1371/journal.pone. 0095255

Hempenstall, K. (2016). Research Report 11 - Read About It: Scientific Evidence for Effective Teaching of Reading. Sydney: Centre for Independent Studies.

Juel, C. (1988). Learning to read and write: a longitudinal study of 54 children from first through fourth grades. J. Educ. Psychol. 80, 437-447. doi:10.1037/ 0022-0663.80.4.437

Lonigan, C. J., Anthony, J. L., Phillips, B. M., Purpura, D. J., Wilson, S. B., and McQueen, J. D. (2009). The nature of preschool phonological processing abilities and their relations to vocabulary, general cognitive abilities, and print knowledge. J. Educ. Psychol. 101, 345-358. doi:10.1037/a0013837

Moore, C., Evans, D., and Dowson, M. (2005). The intricate nature of phonological awareness instruction. Spec. Educ. Perspect. 14, 37-54.

National Institute of Child Health and Human Development. (2000). Report of the National Reading Panel. Teaching Children to Read: An Evidence-Based
Assessment of the Scientific Research Literature on Reading and Its Implications for Reading Instruction (NIH Publication No. 00-4769). Washington, DC: U.S. Government Printing Office.

Nicholson, T. (2007). "How many sounds in ox?" A survey of linguistic knowledge that teachers migth need to teach reading and spelling effectively. Set 2, 29-34.

Quinn, J. M., and Wagner, R. K. (2015). Gender differences in reading impairment and in the identification of impaired readers: results from a largescale study of at-risk readers. J. Learn. Disabil. 48, 433-445. doi:10.1177/ 0022219413508323

Rose, J. (2009). Identifying and Teaching Children and Young People with Dyslexia and Literacy Difficulties. An Independent Report from Sir Jim Rose to the Secretary of State for Children, Schools and Families. Available at: http:// webarchive.nationalarchives.gov.uk/20130401151715/http://www.education. gov.uk/publications/eOrderingDownload/00659-2009DOM-EN.pdf

Rowe, K., and National Inquiry into the Teaching of Reading. (2005). Teaching Reading. Available at: http://research.acer.edu.au/tll_misc/5

Schuele, C. M., and Boudreau, D. (2008). Phonological awareness intervention: beyond the basics. Lang. Speech Hear. Serv. Sch. 39, 3-20. doi:10.1044/01611461(2008/002)

Share, D., and Stanovich, K. (1995). Cognitive processes in early reading development: accommodating individual differences into a model of acquisition. Issues Educ. 1, 1-57.

Sim, S. S., Berthelsen, D., Walker, S., Nicholson, J. M., and Fielding-Barnsley, R. (2014). A shared reading intervention with parents to enhance young children's early literacy skills. Early Child Dev. Care 184, 1531-1549. doi:10.1080/ 03004430.2013 .862532

Sinatra, R., Zygouris-Coe, V., and Dasinger, S. (2011). Preventing a vocabulary lag: what lessons are learned from research? Read. Writ. Q. 28, 333-357. doi:10.1080/10573569.2012.702040

Skibbe, L., Behnke, M., and Justice, L. M. (2004). Parental scaffolding of children's phonological awareness skills: interactions between mothers and their preschoolers with language difficulties. Commun. Disord. Q. 25, 189-203. doi:10.1177/15257401040250040401

Skibbe, L., Justice, L. M., and Bowles, R. P. (2011). Implementation processes associated with a home-based phonological awareness intervention for children with specific language impairment. Int. J. Speech Lang. Pathol. 13, 110-124. doi:10.3109/17549507.2011.524246

Snow, C. E., Burns, M. S., and Griffin, P. (1998). Preventing Reading Difficulties in Young Children Committee on the Prevention of Reading Difficulties in Young Children. Washington, DC: National Research Council.

Snow, P. (2016). Elizabeth Usher Memorial Lecture: language is literacy is language positioning speech-language pathology in education policy, practice, paradigms and polemics. Int. J. Speech Lang. Pathol. 18, 216-228. doi:10.3109/ 17549507.2015.1112837

Woodcock, R. W. (2011). Woodcock Reading Mastery Tests: WRMT-III Manual. London: Pearson.

Conflict of Interest Statement: The Boost program was developed and is delivered by the Dyslexia-SPELD Foundation. MN is the Executive Officer of the Dyslexia-SPELD Foundation. GB and AP are employees of the Dyslexia-SPELD Foundation. MB, SL, and MC are members of the Dyslexia-SPELD Foundation. One of the funders, United Way West Australia, supported the development of the Boost program and funds the Dyslexia-SPELD Foundation to deliver the program.

Copyright $\odot 2017$ Boyes, Leitão, Claessen, Dzidic, Boyle, Perry and Nayton. This is an open-access article distributed under the terms of the Creative Commons Attribution License (CC BY). The use, distribution or reproduction in other forums is permitted, provided the original author(s) or licensor are credited and that the original publication in this journal is cited, in accordance with accepted academic practice. No use, distribution or reproduction is permitted which does not comply with these terms. 